\title{
Simulation Study of Coal Failure Law under High-Pressure Water Jetting
}

\author{
Beifang GU*,Yanli DENG,Yan SHI
}

\begin{abstract}
High-pressure water jetting impinging on coal plays a relatively important role in improving pressure relief and permeability of the coal body, which can elevate the gas drainage effect and eliminate the outburst danger. But the slot formed by high-pressure water jetting impinging on the coal is affected by various factors in pressure relief and permeation of the surrounding coal. To explore how to improve the effect of pressure relief and permeability of the coal body in the process of high-pressure water jetting, the stress-strain and failure of the surrounding coal after the formation of slots were analyzed based on Fast Lagrangian Analysis of Continua 3D(FLAC3D) software, the influence and law exerted from each of the factors was screened out on pressure relief of the slot, and the mathematical model of the slot failure range was constructed. Results show that stress of slots impinged by high-pressure water jetting changes considerably in different directions. As vertical stress increases, the range of pressure relief and failure of the coal body gradually increase, and the pressure relief range enlarges exponentially with the increase of depth. The synergy pressure relief between slots can strengthen the pressure relief of the coal body. The findings obtained from this study can provide construction guidance and reference value for the onsite application of related hydraulic measures.
\end{abstract}

Keywords: Failure law; High-pressure water jetting; Numerical simulation; Pressure relief effect

\section{INTRODUCTION}

Considering the special energy structure in China, coal has dominated the national energy consumption structure for a long time [1-4]. A huge amount of gas can be contained in many coal seams, which poses great safety threats to coal mining. For example, fire accidents resulting from the outburst of coal and gas must be eliminated urgently [5-6]. Gas, as a clean energy source, has minimal environmental pollution during utilization, and its application potential can be widely tapped [7, 8]. This feature makes gas mining a focus in the field of coal mines. However, many coal seams are characterized by large stress and poor permeability, which directly lead to low gas extraction efficiency [9]. High-pressure water jetting is used to impinge on the coal body, coming out of a slot to make the deep coal move and enhance the pressure relief and permeability of the coal body, thereby reducing the stress and unlocking the penetrating channel of gas [10]. Thus, the permeability of the coal body and the gas extraction are enhanced. This hydraulic method has been widely applied [11]. The improvement of coal seam permeability is affected ultimately due to the large mechanical parameters of different coal seams, compounded with various effects caused by the same highpressure water jetting measures. Thus, it is greatly important for the application of hydraulic measures through studying destruction law of coal impinged by highpressure water jetting.

Most previous studies on improving high-pressure water jetting are only applicable to a specific coal mine based on a specific coal seam condition [12], and lack a comprehensive consideration of various influencing factors of high-pressure water jetting to improve coal permeability because different influencing factors affect others in different degrees. The correct and rapid setting of parameters during the application of the hydraulic measure is insufficient in existing studies and applications, and a model that can quickly obtain the application parameters of high-pressure water jetting measures must be studied based on relevant mechanical parameters of the coal body. Therefore, this study examines the coal destruction impinged by high-pressure water jetting by using Fast Lagrangian Analysis of Continua 3D(FLAC3D) software. Subsequently, the law and finding ways to determine the coal damage range are summarized via hydraulic measures. This study aims to provide a feasible solution to the problem that the damage range coming out of the hydraulic onsite application is difficult to determine.

\section{STATE OF THE ART}

According to the problem of high-pressure water jetting impinging on the coal body to reduce the stress and improve the permeability of the coal body, the existing literature discusses the influence of a specific mine or an influencing factor on pressure relief and permeability enhancement of the coal body.

Although several references on improving pressure relief and permeability of coal seam are available from previous research, the existing literature mostly starts the research through understanding a series of pressure relief and permeability enhancement effects of a coal body with the participation of a specific coal mine and influencing factors. Previous research lacks a comprehensive consideration of various influencing factors of highpressure water jetting to improve coal permeability, and different influencing factors will affect others in different degrees. Research on the correct, rapid setting of parameters during the application of the hydraulic measure is insufficient, and a model that can quickly obtain the application parameters of high-pressure water jetting measures must be studied based on relevant mechanical parameters of the coal body.

Therefore, this study sets the typical model parameters, analyzes the stress-strain and failure of the surrounding coal after the formation of slots, examines each effect of various influencing factors on the pressure relief effect of the slot, studies the effect of synergy pressure relief under different slot arrangements, and finally designs the mathematical model of slot failure range based on numerous numerical simulations of the same type, previous studies, and application of FLAC3D software platform to address the shortcomings of existing 
studies. Moreover, this study offers a method for quickly determining appropriate parameters for the field application of hydraulic measures.

The remaining chapters of this study are organized as follows: Section 3 introduces and analyzes the applicability of FLAC3D software as well as establishes the numerical calculation model. Section 4 analyzes and discusses the results. Section 5 presents the conclusions.

\section{METHODOLOGY}

\subsection{FLAC3D Software Introduction and Applicability Analysis}

FLAC3D numerical simulation software is suitable for replicating mechanical changes of materials such as rock and soil, especially for plastic rheological characteristics. This method can obtain data faster and more accurately compared with other methods $[25,26]$.

\subsection{Establishment of the Numerical Calculation Model}

Parameters of numerical calculation model are set according to the actual situation of a typical coal seam. First, a numerical model is needed, combined with an Excel model. A cuboid model is built considering actual onsite situation, computer performance, and time required for calculation. The outermost surrounding rock establishes a radial grid around the outside of the cylinder. It only bears crustal stress because it is far from the borehole, thus encountering difficulty in producing deformation and damage. Hence, the larger grid is set as well. The unit of the numerical model is set to $1 \mathrm{~m}$ in the $X$ and $Z$-axis directions, and $0.05 \mathrm{~m}$ in the $Y$-axis direction. A cylindrical shell grid is built on the inner wall rock. It is easy to deform and destroy because it is close to the borehole; thus, the grid is smaller. The cell is $0.5 \mathrm{~m}$ in the $X, Y$, and $Z$-axis directions. The core part of the model is the cylindrical drilling model, and the cell unit body is set to $0.25 \mathrm{~m}$ in the $X$-axis and $Z$-axis, and $0.05 \mathrm{~m}$ in the $Y$ axis. The model is duplicated with a length of $17 \mathrm{~m}$, an inclination of $10 \mathrm{~m}$, and a vertical of $17 \mathrm{~m}$ to satisfy numerical calculation; slot depth is designated as $1 \mathrm{~m}$ according to limitations of computer hardware.

The numerical calculation model is divided into 53600 units. Based on the onsite situation, the operation surface of the model is set to the $X$-axis, and the inclination direction is the $Y$-axis. The slot model is partially enlarged to facilitate observation, as shown in Fig. 1.
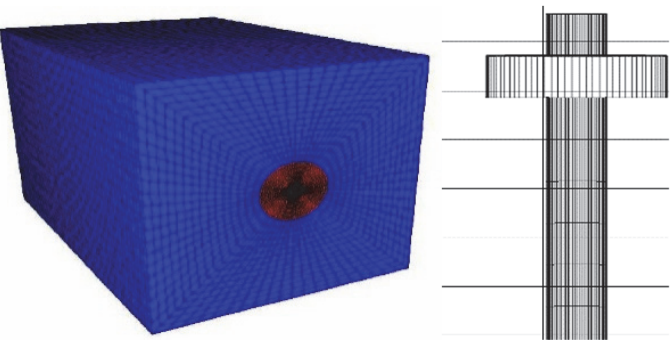

Figure 1 Numerical simulation model and hydraulic cutting model

Second, numerical calculation needs to assign values to the model. Parameter assignment is determined according to experiments or related data for accuracy of numerical simulation results. Numerical model material assignment parameters are shown in Tab. 1.

Table 1 Mechanical parameters in numerical simulation

\begin{tabular}{|c|c|c|c|c|c|}
\hline 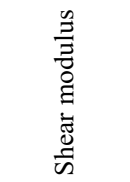 & 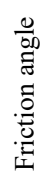 & 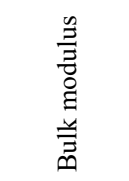 & 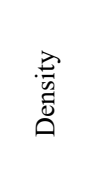 & 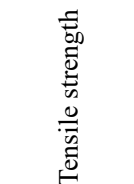 & $\frac{\tilde{0}}{\frac{0}{\tilde{d}}} \frac{0}{0}$ \\
\hline $\mathrm{Pa}$ & $\circ$ & $\mathrm{Pa}$ & $\mathrm{kg} / \mathrm{m}^{3}$ & $\mathrm{~Pa}$ & $\mathrm{~Pa}$ \\
\hline $0.19 \times 10^{9}$ & 20 & $0.36 \times 10^{9}$ & 1400 & $0.03 \times 10^{6}$ & $1 \times 10^{6}$ \\
\hline
\end{tabular}

The numerical calculation model should be initialized with the reference of the actual situation. The self-weight stress field and horizontal tectonic stress field must be provided during initialization. The vertical stress field applied to the model gradually increases as the vertical depth magnifies to obtain more real data. The displacement and velocity of the model in the horizontal and vertical directions are fixed. Numerical simulation adopts the Mohr-Coulomb constitutive model, whose calculation accuracy is set to $10-5$ according to the timeliness and accuracy of the simulation.

After finalizing numerical simulation, stress-strain and changes of the plastic area appearing near the coal body are recorded through a cloud chart, and the effect of the slot on the surrounding coal is studied qualitatively and quantitatively.

After selecting appropriate crustal stress parameters, the model must be initialized with stress to balance the initial crustal stress. The stress cloud diagram after crustal stress initialization is shown in Fig. 2.

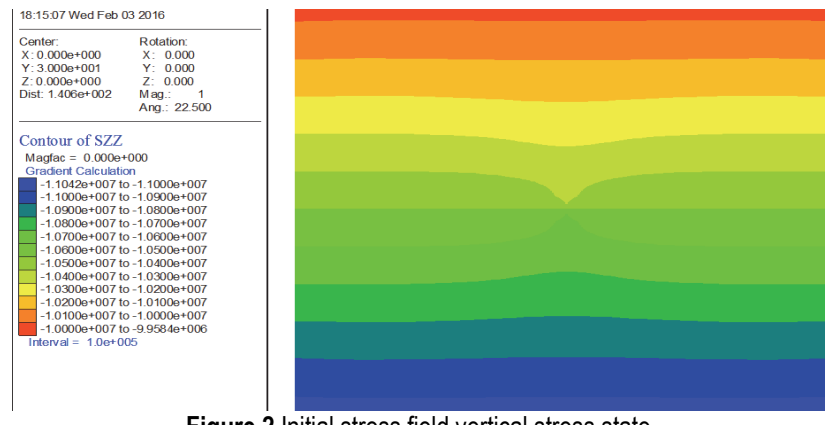

Figure 2 Initial stress field vertical stress state

\section{RESUILT ANALYSIS AND DISCUSSION}

4.1 Analysis on Influence of Pressure Relief of the Coal Surrounding the Slot

This section provides a reference for subsequent numerical simulation by studying changes in stress, strain, and plastic zone of the coal surrounding the slot during the impinging process of high-pressure water jetting.

\subsubsection{Stress Variation Law of Coal Surrounding the Slot}

Basic parameters of the numerical model are set as follows: the slot is set in a depth of $1 \mathrm{~m}$, a width of $0.2 \mathrm{~m}$, and a water jetting pressure of $30 \mathrm{MPa}$. The simulated model is sliced, as shown in Fig. 3, where Fig. 3a, Fig. 3b, and Fig. $3 \mathrm{c}$ are slices perpendicular to the $Y, Z$, and $X$-axis, respectively, and each represents stress distribution clouds in the respective directions of the model. Fig. 3d, Fig. 3e, 
and Fig. $3 \mathrm{f}$ are slices perpendicular to the $Y, Z$, and $X$-axis, respectively, and each represents stress distribution clouds in the respective directions of the model. The stress cloud diagram shows the stress distribution of the coal surrounding the slot. The stress gradually decreases in the $X$ and $Y$-axis directions and is symmetrically distributed with the center of symmetry at the midpoint of the slot. The stress distribution of the coal surrounding the slot gradually decreases in the $Y$-axis direction with a symmetry "butterfly" layout, whose symmetry center is also at the midpoint of the slot. Stress distribution law in the $Z$-axis direction is similar to that in the $X$-axis, showing a gradually and symmetrically decreasing trend from the vicinity to the center of the slot.

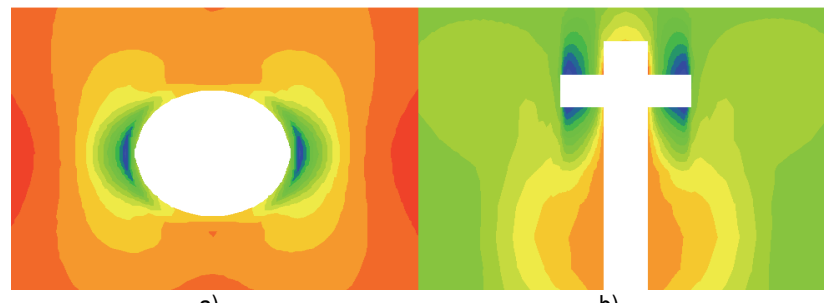

a) b)

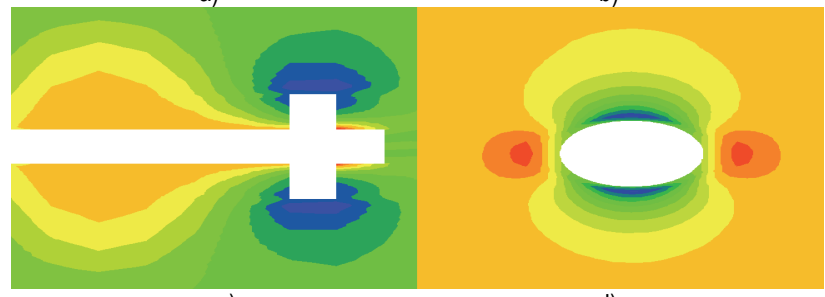

c)

d)

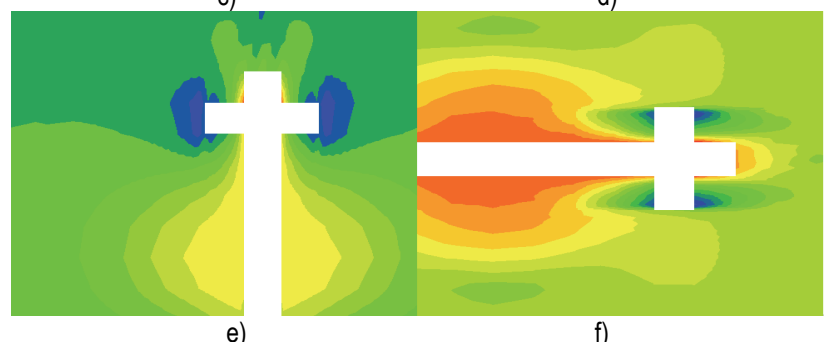

Figure 3 Stress distribution cloud of single slotting
Observation points are set at different positions from the slot center in the model, stress values at each observation point are calculated after numerical simulation is completed, and corresponding stress concentration coefficients are calculated to carry out quantitative analysis. Tab. 2 shows that stress variation law is the same as the cloud diagram, that is, the stress is at the same distance from the center point of the slot, and the degree of stress relief in the $Y$-axis direction is much greater than that in the $X$ and the $Z$-axis directions.

Fig. 4 displays variation law of stress unloading volume of the coal body corresponding to different stress concentration coefficients in $X, Y$, and $Z$-axis directions. In the entire stress concentration factor range, stress unloading volume decreases when stress concentration factor increases, which is consistent with stress distribution law studied previously. When stress concentration factor is large, stress concentration factor in the $Y$-axis direction is greater than in the two other directions because the depth of the slot is much larger than the width, resulting in a larger stress unloading in the $Y$-axis direction. By contrast, the degree of stress relief in the $Y$-axis direction is smaller than that in the $X$-axis direction when the stress concentration factor is small because the influence of pressure relief is much better than that in the $Y$-axis direction when the $X$-axis direction has a greater slot depth than the $Y$-axis direction. Fig. 4 shows that stress unloading volume increases in different directions at various speeds. As stress concentration factor magnifies, stress unloading volume in each direction decreases, and speed gradually increases. When stress concentration factor increases, stress relief volume in the $Y$-axis direction decreases, and speed decreases compared with other directions. When slot width is much smaller than the slot depth, the pressure relief effect in the $Y$-axis direction is better than that in the two other axis directions.

Table 2 Stress concentration factor of different center distances

\begin{tabular}{|c|c|c|c|c|c|c|c|c|}
\hline $\begin{array}{c}\text { Position- } \\
X \\
/ \mathrm{m}\end{array}$ & $\begin{array}{c}\text { Stress } \\
\text { unloading } \\
/ \mathrm{MPa}\end{array}$ & $\begin{array}{c}\text { Stressconcentrationfactor } \\
\qquad / \%\end{array}$ & $\begin{array}{c}\text { Position- } \\
Y \\
/ \mathrm{m}\end{array}$ & $\begin{array}{c}\text { Stress } \\
\text { unloading } \\
/ \mathrm{MPa}\end{array}$ & $\begin{array}{c}\text { Stressconcentrationfactor } \\
/ \%\end{array}$ & $\begin{array}{c}\text { Position- } \\
Z \\
/ \mathrm{m}\end{array}$ & $\begin{array}{c}\text { Stress } \\
\text { unloading } \\
/ \mathrm{MPa}\end{array}$ & $\begin{array}{c}\text { Stressconcentrationfactor } \\
/ \%\end{array}$ \\
\hline 1.3 & 4.8 & 60 & 0.5 & 0.5 & 95 & 1.3 & 5.0 & 50 \\
\hline 1.5 & 6.5 & 50 & 1.0 & 2.0 & 80 & 1.5 & 6.7 & 40 \\
\hline 1.8 & 8.5 & 30 & 1.5 & 4.3 & 70 & 1.8 & 8.0 & 20 \\
\hline 2.0 & 9.0 & 30 & 2.0 & 11.0 & 20 & 2.0 & 9.2 & 10 \\
\hline 2.2 & 11.0 & 20 & 2.5 & 11.0 & 10 & 2.2 & 9.7 & 10 \\
\hline
\end{tabular}

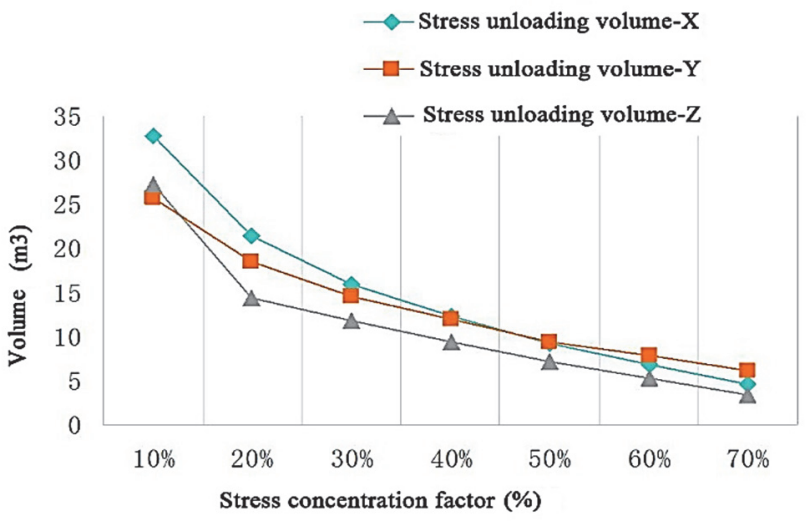

Figure 4 Relationship between concentration factor and unloading volume
After hydraulic measures are completed, stress at the edge of the slot is zero. The coal body is forced to move from the edge to the deep part due to the existence of a pressure gradient. When distance from the slot is great, stress concentration coefficient is low. The slot plays a key role in pressure relief for the coal in the nearer position, but this pressure relief effect decreases rapidly with the increase of the distance. This analysis shows that stress concentration factor in the $Y$-axis direction is larger than that in other directions due to the geometry particularity of the slot, resulting in a better stress unloading effect in the $Y$-axis direction. 


\subsubsection{Failure Law of the Coal Surrounding the Slot}

The above research results show that the difference of distance between coal and slot generates a varied stress distribution, which is consistent with the difference with the stress concentration factor. When stress on part of the coal exceeds the limit, the coal body will break and enter a plastic state, stability of the coal body in the plastic state is extremely poor, many cracks will appear inside, and strength of the coal body drops sharply. As internal cracks in the coal body expand, the permeability of the coal body increases dramatically, and the coal gas migration channel is dredged, together with the accelerating speed of gas migration to the slot. The drainage effect can eliminate outburst risks via a connected pipe. Compared with other regions, the coal body in the plastic state is in danger of outburst due to the small internal elastic potential energy and gas kinetic energy as well as no condition for the occurrence of dynamic phenomena. The range of the coal surrounding the slot in the plastic zone is shown in Fig. 5.

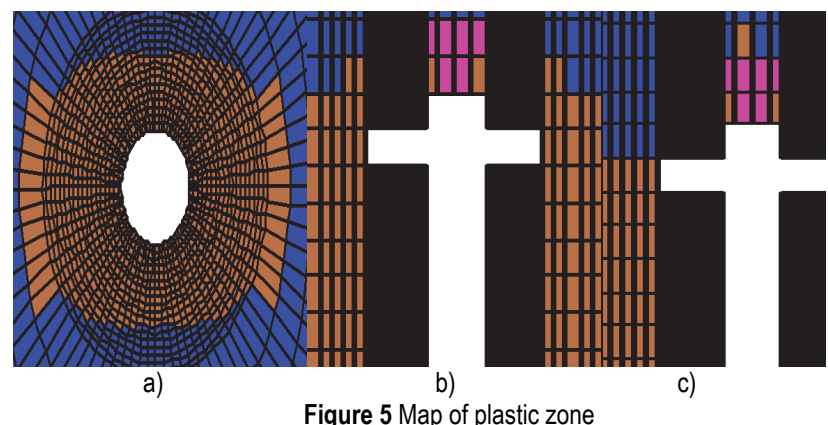

The model is sliced for easy observation. Fig. 5a, Fig. 5b, and Fig. 5c are slices perpendicular to the $X, Y$, and $Z$ axis, respectively. Fig. 5a shows that the model has an elliptical distribution in the plastic area perpendicular to the $Y$-axis direction. The plastic damage area is larger in the horizontal direction than in the vertical direction. Generally, the horizontal stress on the borehole is greater than the vertical stress; thus, the slot built in the horizontal direction is easily destroyed. Fig. 5b illustrates that the influence exerted on the surrounding coal after the formation of the slot is much greater than that of the drainage borehole, which also shows that the effect of hydraulic gas extraction is more substantial than that of drilling gas only. The area where the coal body is under plastic destruction is much larger in parallel to the horizontal direction of the borehole than perpendicular to the borehole because the slots' depth is greater than its width. The whole model illustrates that the coal body in the plastic zone shows a distribution similar to the slot model, with a larger diameter and plastic zone in the $Y$-axis direction (see Fig. 5c). Observation points at different distances from the slot center are installed to investigate the degree of stress unloading at the boundary of the plastic zone. Stress unloading at the boundary of the plastic zone reaches a high level, indicating that all coal bodies in the plastic zone are relieved of pressure. For field application, the radius of the slot influence range can be formulated according to the range of the plastic zone, which can better reflect the pressure relief area and avoid the occurrence of gas drainage blind areas.

\subsection{Analysis of Synergy Pressure Relief between Slots}

In practical applications, the coal body between the slots will be jointly affected by multiple slots, thus changing the pressure relief effect. This section summarizes mutual influence law of pressure relief in the case of multi-slot drilling by studying parallel arrangement and staggered arrangement between drillers.

\subsubsection{Effect of Parallel Relief between Boreholes}

The relevant model is depicted in Fig. 6. Numerical calculation model parameters are $400 \mathrm{~m}$ depth of coal seam, $30 \mathrm{MPa}$ of water-jetting pressure, $1 \mathrm{~m}$ depth of slot, $0.2 \mathrm{~m}$ width of slot, and $5 \mathrm{~m}$ spacing distance of slots. The stress changing cloud diagram of the coal body is displayed in Fig. 7, and the range of the plastic zone is shown in Fig. 8.
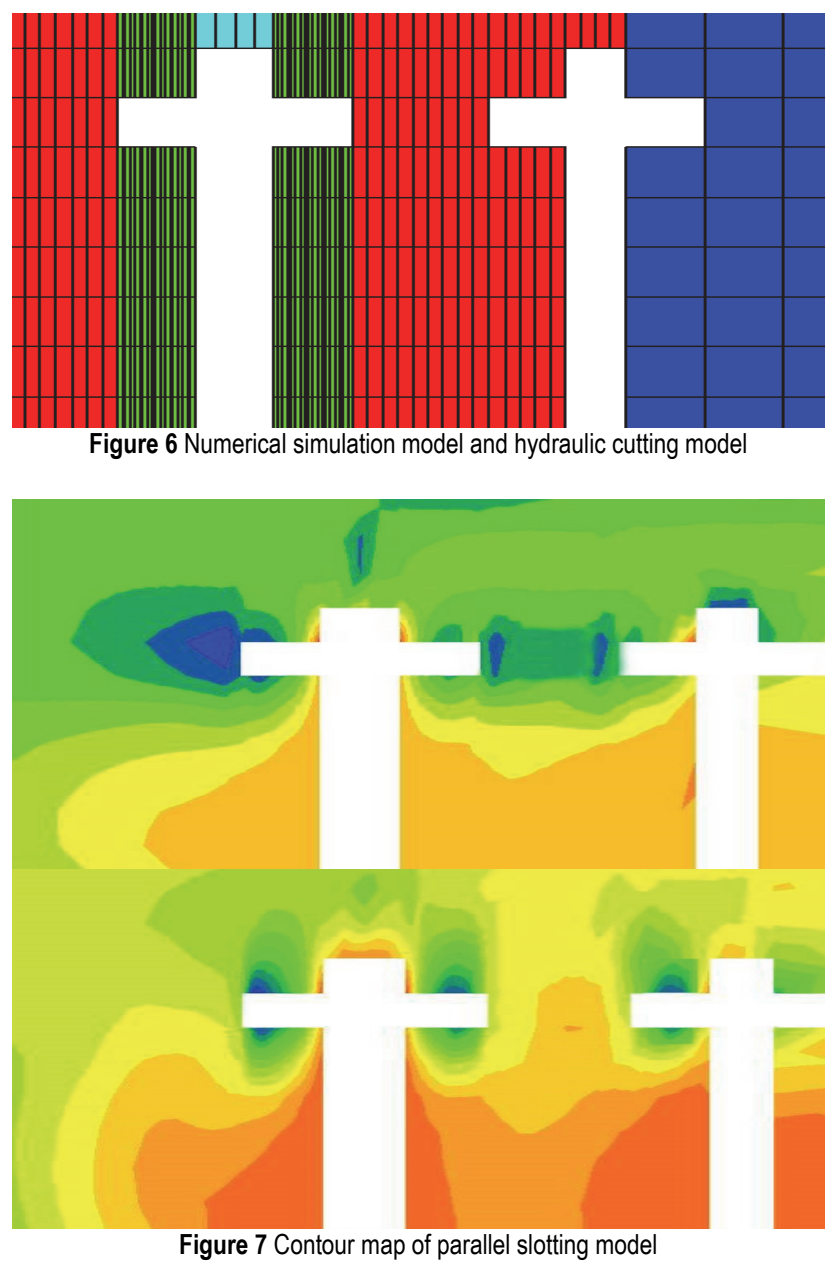

The stress-strain cloud diagram shows that when the distance between two horizontally adjacent boreholes is 5 $\mathrm{m}$, the range of pressure relief gradually increases from starting to completion of the construction, compounded with the expanding displacement range of the coal body. The coal body in the middle of the two slots is affected by the deformation of the coal bodies on both sides; thus, the pressure relief range of the middle coal is greater than that of a single hydraulic measure. When numerical simulation is completed, all coal bodies between the two horizontally adjacent hydraulic measures are relieved of pressure. 
The plastic damage area diagram has shown eliminated that the coal body is jointly affected by the hydraulic measures on both sides, causing the degree of plastic destruction to be greater than when a single hydraulic measure is drilled. When numerical simulation is completed, the coal body between the two horizontally adjacent hydraulic measures boreholes undergoes plastic deformation completely under the influence of the slot effect, which confirms the synergy pressure relief effect when the slot and borehole are arranged adjacently.

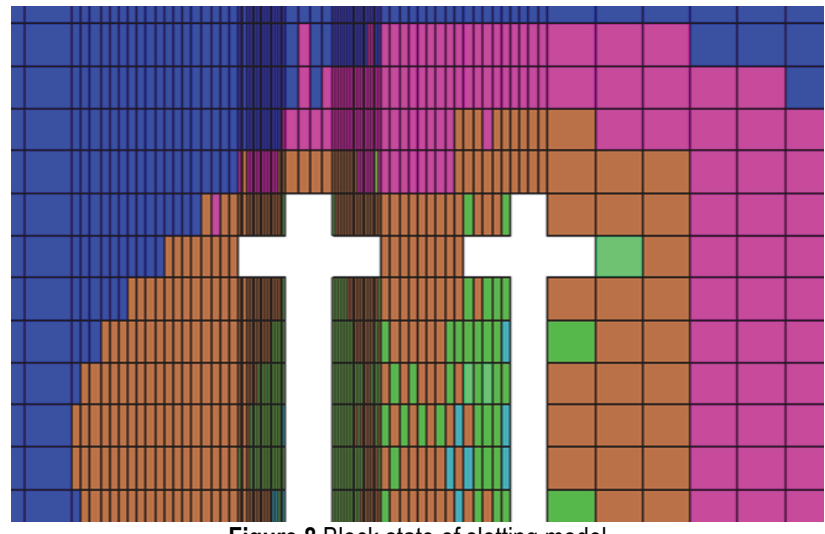

Figure 8 Block state of slotting model

\subsubsection{Pressure Relief in the Staggered Arrangement between the Slot and the Borehole}

This section examines the effect of mutual pressure relief when hydraulic measures intersect in the borehole. The numerical calculation model arranges a $5 \mathrm{~m}$ distance of two centers between the slot and borehole in the $X$-axis and $2 \mathrm{~m}$ in the $Y$-axis, as shown in Fig. 9. Changes in stress and the plastic zone due to the influence on coal affected by staggered arrangement of the coal seam between the two slots are shown. The stress cloud diagram is shown in Fig. 10, and the plastic zone is displayed in Fig. 11.

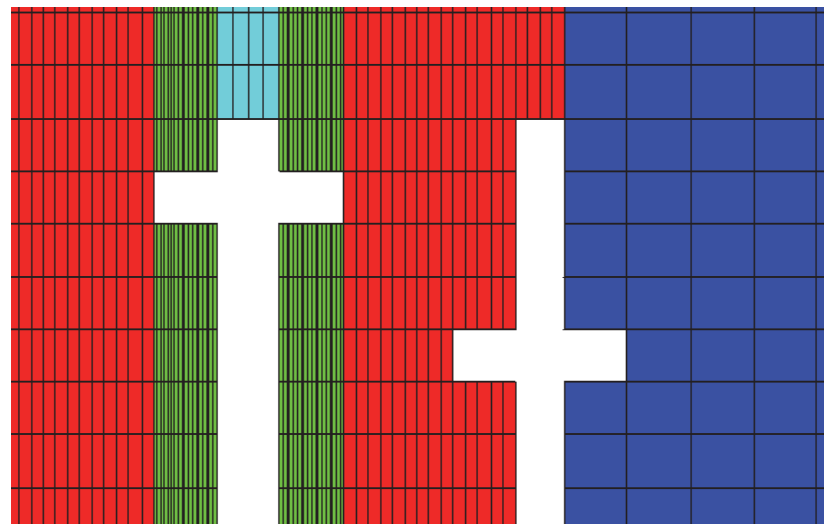

Figure 9 Numerical simulation model and hydraulic cutting model

Fig. 10 shows that when the two hydraulic measures are arranged in a staggered manner, the coal body between the two slots is affected by pressure relief in the $X$ and $Y$ axis directions. In the wake of pressure relief in the two axes, the degree of pressure relief is greater than when drilling with a single hydraulic measure. When numerical simulation is completed, the coal body between the two hydraulic measures is comprehensively relieved of pressure.

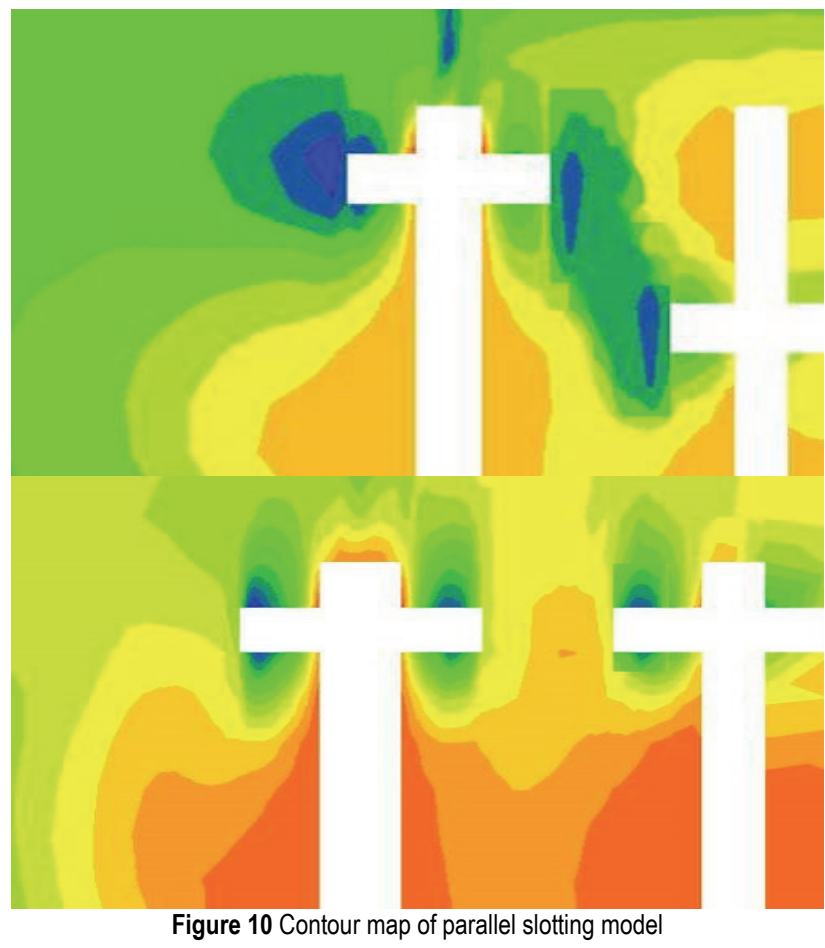

Fig. 11 shows that the degree of plastic failure poses greater threats than a single hydraulic measure used for drilling because the coal body is under the control of slots in different directions. When numerical simulation is finished, the coal body between the two hydraulic measures has been plastically damaged by the effect of the staggered slots. Therefore, the measures of staggered arrangement between slotted holes can effectively increase the pressure relief range and reduce the work of measures.

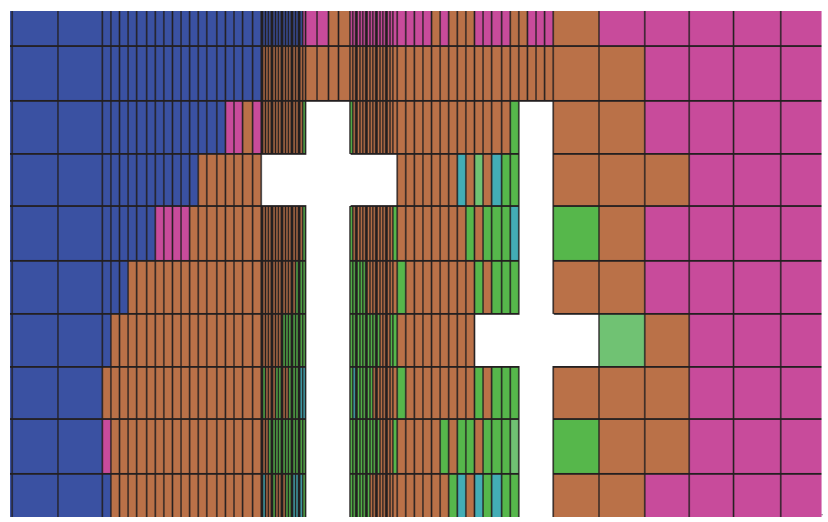

Figure 11 Block state of slotting model

\subsection{Mathematical Model of Coal Failure Radius}

Several sets of numerical simulations with a staggered parameter are added given the lengthy duration of numerical simulation and the difficulty of clarifying the failure radius of coal under different conditions in field applications. In general, factors that affect the failure radius of coal include crustal stress, and depth and width of the slot. The radius of destruction should be calculated separately in the $X, Y$, and $Z$-axis because the slot is discshaped. Previous research on the width and depth of the slot found that the influence of slot depth on the plastic zone in the $Y$-axis direction is considerable, but that on the $X$ and $Z$-axis is less; slot width is totally contrary to slot 
depth. Therefore, the mathematical model must be simplified. According to geometric characteristics of the slot, destruction radius of the coal body in all directions is formulated as follows:

$\left\{\begin{array}{l}X=r+\Delta(X) \\ Y=d+\Delta(Y) \\ Z=r+\Delta(Z)\end{array}\right.$

In Eq. (1), $r$ is the slot depth; $d$ is the slot width. $F$ is the crustal stress. $\Delta(X), \Delta(Y)$ and $\Delta(Z)$ represent the range of plastic zone in all directions.

Crustal stress is expressed by buried depth, $F=\gamma H$. A numerical simulation program is designed with a staggered setting of various parameters to obtain $\Delta(X), \Delta(Y)$ and $\Delta(Z)$, as shown in Tab. 3.

Table 3 The relationship between the parameters of plastic area

\begin{tabular}{|c|c|c|c|c|c|}
\hline $\begin{array}{c}\text { Depth / } \\
\mathrm{m}\end{array}$ & $\begin{array}{c}\text { Slot } \\
\text { width / } \\
\mathrm{m}\end{array}$ & $\begin{array}{c}\text { Slot } \\
\text { depth / } \\
\mathrm{m}\end{array}$ & $\begin{array}{c}\text { Plastic } \\
\text { range- } X / \mathrm{m}\end{array}$ & $\begin{array}{c}\text { Plastic } \\
\text { range- } Y \text { / m }\end{array}$ & $\begin{array}{c}\text { Plastic } \\
\text { range- } Z \text { / m }\end{array}$ \\
\hline 400 & 0.1 & 1.0 & 1.188 & 3.105 & 0.875 \\
\hline 400 & 0.2 & 1.0 & 2.932 & 3.105 & 2.412 \\
\hline 400 & 0.3 & 1.0 & 4.488 & 3.105 & 3.989 \\
\hline 600 & 0.1 & 1.0 & 3.785 & 4.688 & 1.322 \\
\hline 600 & 0.2 & 1.0 & 5.522 & 4.688 & 2.867 \\
\hline 600 & 0.3 & 1.0 & 6.988 & 4.688 & 4.442 \\
\hline 800 & 0.1 & 1.0 & 4.665 & 6.255 & 2.734 \\
\hline 800 & 0.2 & 1.0 & 6.291 & 6.255 & 4.292 \\
\hline 800 & 0.3 & 1.0 & 7.921 & 6.255 & 5.861 \\
\hline 400 & 0.2 & 0.5 & 2.932 & 1.876 & 2.412 \\
\hline 400 & 0.2 & 1.0 & 2.932 & 3.105 & 2.412 \\
\hline 400 & 0.2 & 1.5 & 2.932 & 4.341 & 2.412 \\
\hline 600 & 0.2 & 0.5 & 5.522 & 3.465 & 2.867 \\
\hline 600 & 0.2 & 1.0 & 5.522 & 4.688 & 2.867 \\
\hline 600 & 0.2 & 1.5 & 5.522 & 5.920 & 2.867 \\
\hline 800 & 0.2 & 0.5 & 6.291 & 5.036 & 4.292 \\
\hline 800 & 0.2 & 1.0 & 6.291 & 6.255 & 4.292 \\
\hline 800 & 0.2 & 1.5 & 6.291 & 7.395 & 4.292 \\
\hline & & & & & \\
\hline
\end{tabular}

Matlab is applied to fitting, generating the range of the plastic area:

\footnotetext{
$\Delta(X)=0.00433 H+16.46 d-2.192$

$\Delta(Y)=0.0079 H+2.462 r-2.517$

$\Delta(Z)=0.00468 H+15.58 d-2.588$
}

When Eq. (2) is brought into Eq. (1), fracture radius of the slot in all directions can be obtained as follows:

$\left\{\begin{array}{c}X=r+0.00433 H+16.46 d-2.192 \\ Y=d+0.0079 H+2.462 r-2.517 \\ Z=r+0.00468 H+15.58 d-2.588\end{array}\right.$

Destruction range of the slot in all directions can be quickly determined in field application through this mathematical model, which provides a reference for the drilling arrangement of hydraulic measures.

\section{CONCLUSIONS}

To solve the problem of slot's damage and range formed during high-pressure water jetting impinging on coal and to improve the pressure relief and permeability of the coal body, the stress-strain and destruction of coal surrounding the slot during the impinging of high-pressure water jetting and mutual influences between slots were analysed, a mathematical model of slot damage range was duplicated by conducting numerous simulations. The following conclusions are drawn:

(1) A long, narrow slot is incubated from the coal within the impinging of high-pressure water jetting, simultaneously forming a stress gradient of the coal surrounding the slot. The stress gradient drives the coal body to gradually move toward the slot, thereby releasing stress. This experiment increases the number of cracks in the coal body, improves the gas drainage effect, and solves the problem of low-permeability coal seam drainage.

(2) Mutual influence between slots can improve the pressure relief effect of the coal between adjacent slots. The pressure relief effect is more substantial when drill holes are arranged in a cross. In practical applications, using a staggered arrangement can appropriately increase spacing between boreholes to improve engineering efficiency and finally solve the problem of low construction efficiency.

(3) Through the cross numerical simulation of various factors, destruction range of the slot in different directions under different combinations of factors is obtained. The mathematical model of the coal damage range around the slot is fitted by MATLAB. The model provides a method for quickly determining slot damage range according to the coal body and equipment conditions, which can provide a reference for field application.

The conclusions in this study are based on the highpressure water jetting impinging on the coal platform built by numerical simulation software. The platform can intuitively be aware of the stress-strain and failure of the coal surrounding the slot, providing a convenient method for studying law of pressure relief and permeability enhancement of complex coal bodies, and a quick way to determine destruction range of the coal for the application of onsite hydraulic measures. However, it needs more efforts on resolving the fluid-solid coupling problem of gas-bearing coal rocks.

\section{REFERENCES}

[1] Zhang, S. S.,Wu, C. F.,Liu, H. (2020). Comprehensive characteristics of pore structure and factors influencing micropore development in the Laochangmining area, eastern Yunnan, China. Journalof Petroleum Science and Engineering, 190(2), 128-145. https://doi.org/10.1016/j.petrol.2020.107090

[2] Wang, W. J., Li, F., Wang, A. F.,et al. (2020). Study on substitutable value of electric heating instead of coal heating in northern China under carbon constraints. Journalof Cleaner Production, 260(2), 1879-1786. https://doi.org/10.1016/j.jclepro.2020.121155

[3] Wang, Q., Li, R. (2017). Decline in China's coal consumption: An evidence of peak coal or a temporary blip? Energy Policy, 20(12), 4476-4487. https://doi.org/10.1016/j.enpol.2017.06.041

[4] Kumar, H., Mishra, M. K., \& Mishra, S. (2018). Effect of permeability and geomechanical properties on coal matrix during CBM production: An overview. Journal of Engineering Science and Technology Review, 11(2), 160173.

[5] An, F., Yuan, Y., Chen, X., et al. (2019). Expansion energy of coal gas for the initiation of coal and gas outbursts. Fuel, 235(1), 551-557. https://doi.org/10.1016/j.fuel.2018.07.132 
[6] Wang, G., Liu, Q., Yan, G., et al. (2017). Control system of spontaneous combustion in coal gangue dumps: A case study at Yuquan coal mine in China. Technical Gazette, 24(1), 291-300. https://doi.org/10.17559/TV-20161017072701

[7] Huang, X. C., Fan, C., Wang, R., et al. (2019). Study on gas emission prediction of steeply inclined coal seam applied horizontal slice mining. Journal of Engineering Science and Technology Review, 12(2), 17-26. https://doi.org/10.25103/jestr.122.03

[8] Sanchez, N. P., Zheng, C. T., Ye, W. L., et al. (2018). Exploratory study of atmospheric methane enhancements derived from natural gas use in the Houston urban area. Atmospheric Environment, 176, 261-273. https://doi.org/10.1016/j.atmosenv.2018.01.001

[9] Ramandi, H. L., Mostaghimi, P., Armstrong, R. T., et al. (2016). Porosity and permeability characterization of coal: a micro-computed tomography study. International Journal of Coal Geology, 154, 57-68. https://doi.org/10.1016/j.coal.2015.10.001

[10] Yan, H., Li, Q., Zhang, Y., et al. (2018). Optimization of cavitating flow characteristics on RBSS of waterjet pumps. International Journal of Simulation Modelling, 17(2), 271283. https://doi.org/10.2507/IJSIMM17(2)427

[11] Wang, L., Xu, Y. (2019). Study of the law of gradual change of the influence of hydraulic punching under a rational coal output. Arabian Journal of Geosciences, 12(14), 427. https://doi.org/10.1007/s12517-019-4577-8

[12] Krantovska, O., Petrov, M., Ksonshkevych, L., et al. (2019). Numerical simulation of the stress-strain state of complexreinforced elements. Tehnički Glasnik, 13(2), 110-115. https://doi.org/10.31803/tg-20190417112619

[13] Song, W., Liu, S., Pan, H., et al. (2016).Investigation on the design of hydraulic high-speed punching press with a large press force and a long press stroke. Advances in Mechanical Engineering, 8(12). https://doi.org/10.1177/1687814016683601

[14] Szott, W., Małgorzata, S. V., Gołąbek, A., et al. (2018). Numerical studies of improved methane drainage technologies by stimulating coal seams in multi-seam mining layouts. International Journal of Rock Mechanics and Mining Sciences, 108, 157-168. https://doi.org/10.1016/j.jirmms.2018.06.011

[15] Feng, D., Xu, J., Tao, Y., et al. (2017).Development of hydraulic punching test system and its application. Journal of Mining and Safety Engineering, 34(4), 782-788.

[16] Dunlop, E. C., Salmachi, A., McCabe, P. J. (2020). Investigation of increasing hydraulic fracture conductivity within producing ultra-deep coal seams using time-lapse rate transient analysis: A long-term pilot experiment in the Cooper Basin, Australia. International Journal of Coal Geology, 220, 103363. https://doi.org/10.1016/j.coal.2019.103363

[17] Wu, D. F. (2019). Application of hydraulic punching technology in coal seam gas drainage. Coal Mine Modernization, 4, 81-83.

[18] Jacquey, A. B., Urpi, L., Cacace, M., et al.(2018). Far field poroelastic response of geothermal reservoirs to hydraulic stimulation treatment: Theory and application at the GroßSchönebeck geothermal research facility. International Journal of Rock Mechanics and Mining Sciences, 110, 316327. https://doi.org/10.1016/j.jirmms.2018.08.012

[19] Ren, Z. J. (2019). Application of hydraulic punching technology in seam gas drainage in Yuwu coal mine. Coal Engineering, 81(9), 3534-3585.

[20] Balucan, R. D., Turner, L. G., \& Steel, K. M. (2018). X-ray MCT investigations of the effects of cleat demineralization by $\mathrm{HCl}$ acidizing on coal permeability. Journal of Natural Gas Science and Engineering, 55, 206-218. https://doi.org/10.1016/j.jngse.2018.05.007

[21] Lin, B. Q., Lu, Y. C., Li, B. Y., et al. (2007). High-pressure abrasive hydraulic cutting seam technology and its application in outbursts prevention. Journal of the China Coal Society, 32(9), 959-963.

[22] Chen, Y., Xu, J., Peng, S., et al. (2018). A gas-solid-liquid coupling model of coal seams and the optimization of gas drainage boreholes. Energies, 11(3), 560. https://doi.org/10.3390/en11030560

[23] Fan, C., Li, S., Li, M., et al. (2019). Numerical simulation of hydraulic fracturing in coal seam for enhancing underground gas drainage. Energy Exploration \& Exploitation, 37(1), 166-193. https://doi.org/10.1177/0144598718785998

[24] Feng, X. T., Zheng, X. W., Kong, R., at el. (2016). A novel Mogi type true triaxial testing apparatus and its use to obtain complete stress-strain curves of hard rocks. Rock Mechanicsand Rock Engineering, 49(5), 1649-1662. https://doi.org/10.1007/s00603-015-0875-y

[25] Sun, Y., Zhu, W. Y., Li, B. Z., et al. (2018). Numerical simulation of dry gas migration in condensate gas reservoir. Journal of Power Technologies, 98(2), 212-219.

[26] Yang, Z. K., Sun, Z. Y., Jiang, S. B., et al. (2020). Structural analysison impact-mechanical propertiesof ultra-high hydraulic support. International Journal of Simulation Modelling, 19(1), 17-28.

https://doi.org/10.2507/IJSIMM19-1-498

\section{Contact information:}

\section{Beifang GU, PhD, Lecturer}

(Corresponding author)

School of Environmental and Municipal Engineering,

North China University of Water Resources and Electric Power,

No. 136, East Jinshui Road, Jinshui District,

Zhengzhou, Henan Province, 450046, P. R. China

Email: gubeifang@ncwu.edu.cn

Yanli DENG, PhD, Lecturer

School of Environmental and Municipal Engineering,

North China University of Water Resources and Electric Power,

No. 136, East Jinshui Road, Jinshui District,

Zhengzhou, Henan Province, 450046, P. R. China

E-mail: dengyanli@ncwu.edu.cn

Yan SHI, PhD, Associate Professor

School of Environmental and Municipal Engineering,

North China University of Water Resources and Electric Power,

No. 136, East Jinshui Road, Jinshui District,

Zhengzhou, Henan Province, 450046, P. R. China

E-mail: shiyan@ncwu.edu.cn 